\title{
Bases moleculares de la infección asociada a implantes ortopédicos
}

\author{
Julio J. Contreras y Miguel Sepúlveda
}

\section{The molecular basis of infections associated to orthopedic implants}

Infections associated with the use of orthopedic implants are still the major complication associated with these devices and an unsolved challenge. The frequency of infection associated with orthopedic implant is relatively low, estimated to range between 0.5 to $5 \%$. However, it has devastating consequences for the patient and health institutions. The majority of infections is secondary to gram-positive aerobic microorganisms belonging to the genus Staphylococcus. These bacteria establish chronic infections due to its ability of adhesion and biofilm formation. Biofilms are complex communities in a polysaccharide matrix. This structure retains nutrients and protects the bacteria against the immune response and antimicrobial agents. The study of molecular characteristics and biofilm formation regulation is vital for the understanding of judicious clinical management and the development of novel strategies for the prevention of infection.

Key words: Infection, biofilms, prostheses and implants, prothesis retention.

Palabras clave: Infección, biopelículas, prótesis e implantes, mantención de prótesis in situ.

\section{Introducción}

$\mathrm{E}$ 1 reemplazo articular con protésis, la fijación de fracturas con material de osteosíntesis, la reconstrucción de ligamentos y tendones y otros procedimientos que involucran implantes ortopédicos se han tornado altamente frecuentes en la práctica diaria de la ortopedia y traumatología moderna y están aumentando constantemente en el mundo ${ }^{1,2}$.

La infección asociada a la utilización de implantes ortopédicos, tanto para el manejo de patología degenerativa crónica como de fracturas, es la principal complicación asociada a estos dispositivos y es un desafío aún sin resolver ${ }^{3}$. De hecho, las infecciones asociadas a implantes ortopédicos han ido en aumento los últimos años ${ }^{4}$.

La frecuencia de infección asociada a implante ortopédico es relativamente baja, estimada en un rango entre 0,5 y $5 \%$ para reemplazos articulares (menos de $1-2 \%$ en instituciones con cirujanos altamente experimentados). Sin embargo, posee consecuencias devastadoras, determinando el retiro del implante y su sustitución en la mayoría de las veces, exponiendo al paciente a altos riesgos de recidiva infecciosa ${ }^{1,5,6}$. Es más, la infección de implantes ortopédicos resulta en una seguridad y longevidad alterada del mismo ${ }^{7}$.

Actualmente, las tasas de infección notificadas en reemplazo primario de cadera y de rodilla son $0,3-0,6 \%$ y $1 \%$, respectivamente. Sin embargo, incluso en programas prospectivos de vigilancia se subestiman las tasas de infección; es por esto, que probablemente la tasa sea mayor. El riesgo a corto plazo de infección periprotésica en artroplastia total primaria de cadera y de rodilla es de 0,2 y $0,4 \%$, respectivamente ${ }^{2}$.

En Chile, Otaíza O'R y cols., reportaron una tasa acumulada de 3,5\% de infección protésica de cadera en 28 hospitales (24 públicos). En este estudio de vigilancia se encontraron tasas significativamente mayores en hospitales con menos de 20 operaciones trimestrales promedio (riesgo relativo de 1,72$)^{8}$. Fica y cols., publicaron una tasa de infección articular global de 2,8\% (artroplastía de rodilla y cadera) en el Hospital Clínico de la Universidad de Chile durante el período 1993-19999. Iribarren y cols., reportaron una tasa promedio de infección protésica de cadera de 2,5\% en el Hospital Clínico San Pablo de Coquimbo durante el período 2000-2004 ${ }^{10}$.

El aseo quirúrgico con conservación del implante ortopédico y el uso de antimicrobianos por vía sistémica es la conducta estándar ante esta complicación; sin embargo, no siempre es efectiva ante una infección ya establecida. Muchas veces es necesario el retiro del implante ortopédico, incluso la realización de artrodesis para poder controlar infecciones graves. Las infecciones secundarias a una artroplastia total de cadera y rodilla son una complicación mayor en reconstrucción articular, resultando en morbilidad significativa para el paciente e incremento de los costos hospitalarios ${ }^{1,2}$. Un estudio realizado en Coquimbo calculó el costo promedio de un paciente sin complicación infecciosa (US \$2.354) comparado con un paciente con infección protésica de cadera (US \$ 6.174) $)^{10}$.
Universidad de Chile-Instituto Traumatológico, Santiago. Chile.

No existen conflictos de interés. Financiamiento: Ninguno.

Recibido: 5 de febrero de 2013 Aceptado: 7 de abril de 2014

Correspondencia a: Julio José Contreras Fernández juliocontrerasmd@gmail.com 
Todos los procesos tendientes a lograr una asepsia estricta minimizan la posibilidad de contaminación durante la instalación de implantes ortopédicos, pero son incapaces de controlar totalmente la incidencia de infección ${ }^{5}$.

El riesgo continuo de infección es inherente a la utilización de implantes ortopédicos. Se ha calculado que la presencia de un cuerpo extraño reduce más de 100.000 veces el inóculo mínimo necesario de Staphylococcus aureus para desencadenar una infección ${ }^{2}$. Las infecciones ocurren a pesar del uso de profilaxis antimicrobiana perioperatoria en presencia de un cuerpo extraño, ya que menos de 100 ufc de microorganismos pueden inducir infección ${ }^{11}$.

El uso de antibacterianos profilácticos, a pesar de disminuir la incidencia de infecciones de material ortopédico, no ha logrado prevenir totalmente esta complicación, dado que es frecuente la presencia de multirresistencia antimicrobiana y la posibilidad de diseminación hematógena tardía. Es más, una vez que la infección está establecida y se ha formado una biopelícula (biofilm) en la superficie del implante, las terapias antibacterianas son menos eficaces y la remoción del implante y su sustitución son la única forma de erradicar el problema ${ }^{5}$. A pesar de las estrategias antimicrobianas existentes que son efectivas para el tratamiento de las bacterias en fase planctónica, la mayoría de los antimicrobianos son raramente efectivos contra las biopelículas ${ }^{12}$.

Las infecciones precoces, producidas por microorganismos relativamente virulentos, presentan síntomas y signos agudos, favoreciendo su diagnóstico ${ }^{5}$. A diferencia de las infecciones del post-operatorio precoz y las infecciones protésicas articulares por vía hematógena caracterizadas por un inicio agudo de los signos y síntomas, las infecciones tardías tienen una presentación clínica insidiosa, con signos inflamatorios leves, dolor post-operatorio persistente y/o aflojamiento precoz del implante. La ausencia de estandarización en los criterios para diagnosticar la infección de un implante, sumado a la poca estandarización en la toma de las muestras que deben enviarse a cultivo, llevan a tener una incertidumbre respecto a la real prevalencia de los patógenos asociados ${ }^{1,5}$.

Un paso fundamental y complejo en la práctica ortopédica es la diferenciación de la infección de un implante de una falla del mismo (aflojamiento aséptico) ${ }^{1}$. Hasta ahora, la búsqueda de un único marcador capaz de distinguir entre el aflojamiento aséptico y la contaminación de una infección verdadera ha fallado ${ }^{13}$.

\section{Etiología}

Se ha demostrado categóricamente que la gran mayoría de las infecciones asociadas a implantes ortopédicos es secundaria a microorganismos aerobios grampositivos, principalmente pertenecientes al género Staphylococcus, dentro de los cuales, los más importantes son S. aureus y un amplio número de especies típicamente saprofíticas, capaces de ser dañinas sólo cuando las defensas del hospedero están alteradas ${ }^{1}$.

La investigación se ha enfocado en $S$. aureus y $S$. epidermidis, dos agentes colonizadores de implantes ortopédicos productores de biopelículas. Utilizando la técnica de ribo-impresión, se han detectado múltiples ribo-grupos asociados a infección de implante ortopédico por estos dos agentes 5 .

Cabe recordar que S. epidermidis forma parte de la microbiota cutánea fisiológica del hombre, que $20 \%$ de la población es portadora crónica de S. aureus y $60 \%$ es portador transitorio del mismo ${ }^{14}$. La contaminación del paciente por esta microbiota, no es el problema más grave. A pesar que esta microbiota posee escasa o nula agresividad y baja resistencia antimicrobiana, es rápidamente sustituida en los primeros días de hospitalización ${ }^{15}$. El ambiente hospitalario es un importante reservorio de clones patógenos más virulentos, que son regularmente expuestos a procedimientos desinfectantes y tratamientos antibacterianos. El contacto de los saprófitos regulares con los patógenos hospitalarios lleva a una transmisión horizontal de factores de virulencia y resistencia antimicrobiana a través de transposones (elementos móviles de $\mathrm{ADN})^{1}$.

Otro patógeno que habita el ambiente intestinal humano, Enterococcus faecalis, ha sido reconocido recientemente con una alta prevalencia en infecciones de implantes ortopédicos ${ }^{16}$.

En el Instituto Ortopédico Rizzoli (Bolonia, Italia), desde el año 2000 se guardan muestras de todas las infecciones asociadas a implante ortopédico y son analizadas para identificar la especie, susceptibilidad antimicrobiana con técnica de disco de difusión y caracterizadas para ciertos rasgos de virulencia, tal como la capacidad de formar biopelículas ${ }^{17}$.

De 800 muestras de infecciones asociadas a implantes ortopédicos, $16 \%$ arrojan cultivos polimicrobianos. Aproximadamente $80 \%$ son causadas por especies de Staphylococcus (S. aureus y S. epidermidis, específicamente). Otras especies asociadas a estas infecciones son Staphylococcus hominis y Staphylococcus haemolyticus, representando 13\% de las infecciones. Menos fecuentes son Pseudomonas aeruginosa y E. faecalis ${ }^{18}$. En otras palabras, la infección causada por todas las especies bacterianas exceptuando las especies de Staphylococcus, representan juntos sólo una minoría de las infecciones asociadas a implantes ortopédicos $(22 \%)^{1}$.

Montanaro y cols., analizaron 1.027 muestras obtenidas en el período 2000 a 2003 de 699 pacientes con infección asociada a material ortopédico (prótesis de rodilla, prótesis de cadera, sistemas de fijación interna y externa, y material para reconstrucción de ligamentos y 
tendones). Las especies del género Staphylococcus fueron los agentes etiológicos prevalentes en infección (78,1\% asociado a implante ortopédico y $68,3 \%$ sin implante). Dentro de ellas, $S$. aureus generalmente exhibe la más alta prevalencia $(78,1 \%$ asociado a implante ortopédico y $40,3 \%$ sin implante). Staphylococus epidermidis se perfila como el segundo en prevalencia, pero sólo asociado a implante ortopédico ${ }^{2}$.

Rohde y cols., analizaron 70 infecciones protésicas (52 por $S$. epidermidis y 18 por $S$. aureus), con el objetivo de definir la verdadera importancia patogénica. Para ello realizaron comparaciones genéticas de aislados preoperatorios, post-operatorios y de comensales cutáneos, con tal de confirmar la trascendencia clínica de las cepas aisladas y descartar contaminación ${ }^{19}$. Todas las cepas de $S$. aureus eran capaces de formar biopelículas, en comparación al $69 \%$ de las cepas de S. epidermidis. Se encontró biopelículas en $80 \%$ de los cultivos de prótesis total de rodilla y sólo $54 \%$ en prótesis total de cadera ${ }^{19}$. La formación de biopelículas es una característica ampliamente difundida entre los cultivos aislados de infecciones asociadas a implantes ortopédicos ${ }^{20}$.

En Chile, Otaíza O'R y cols, identificaron al menos un agente etiológico en $60,8 \%$ de las infecciones, con una gran variedad de agentes, predominando los bacilos gramnegativos no fermentadores (33,3\%; Acinetobacter baumannii, Pseudomonas spp) y cocos grampositivos $(23,8 \% \text {; S. aureus, Staphylococcus coagulasa negativa })^{8}$. Fica y cols., reportaron una predominancia del género Staphylococcus (49\%), secundados por bacilos gramnegativos (37\%). En forma individual, S. aureus (30\%) y Staphylococcus coagulasa negativa (19\%) fueron los agentes más frecuentes; de éstos, 50 y $20 \%$ fueron resistentes a cloxacilina, respectivamente'.

Staphylococcus aureus posee una vasta gama de toxinas, que lisan leucocitos, inhiben la activación del complemento, opsonizan y atraen (quimiotaxis de) neutrófilos, neutralizan las defensinas, alteran la respuesta inmune humoral causando inmunosupresión a través de superantígenos, resguardan el hierro a través de sideróforos y sobreviven incluso a la fagocitosis leucocitaria ${ }^{5}$. Sin embargo, la amplia gama de factores de virulencia putativos codificados en el genoma de $S$. aureus ha impedido, a pesar de muchos intentos, revelar el factor de virulencia dominante. En S. aureus, el llamado "virulón", consiste en aproximadamente 50 genes accesorios relacionados con el proceso de infección ${ }^{2}$. Por su parte, $S$. epidermidis primariamente forma biopelículas para sobrevivir ${ }^{5}$.

Staphylococcus aureus siempre ha exhibido niveles alarmantes de resistencia antimicrobiana y las bacterias que forman biopelículas en las superficies de los implantes son particularmente resistentes a los antimicrobianos per se y tienden a sobrevivir a la antibioticoterapia agresiva, incluso en ausencia de factores de resistencia específi- $\cos ^{1}$. La resistencia contra $\beta$-lactámicos (especialmente penicilinas) en $S$. aureus y $S$. epidermidis es frecuente. En el Instituto Ortopédico Rizzoli, $80 \%$ de las infecciones son causadas por especies resistentes a cefalosporinas; aún más, si el agente etiológicos es Staphylococcus la resistencia a meticilina/oxacilina alcanza a $40 \%{ }^{21,22}$.

La administración de antimicrobianos locales a través de cemento óseo cargado con antibacterianos representa una manera exitosa y costo-efectiva para prevenir infecciones asociadas a implantes ortopédicos ${ }^{23}$. Sin embargo, la eficacia clínica de los cementos óseos cargados con antibacterianos ha sido cuestionada y existe preocupación acerca de la contribución de su uso en el desarrollo de resistencia antimicrobiana ${ }^{23}$, ya que la susceptibilidad de Staphylococcus spp a gentamicina ha disminuído enormemente desde la introducción del cemento óseo cargado con este antibacteriano ${ }^{23}$.

\section{Patogénesis de la infección asociada a implante ortopédico}

La patogénesis de la infección asociada a implante ortopédico difiere de otras infecciones post-quirúrgicas por la presencia de biomateriales y la formación de biopelículas $^{1}$ (Figura 1). La dosis crítica de microrganismos contaminantes requeridos para producir una infección es mucho menor en presencia de material foráneo en el sitio quirúrgico ${ }^{24}$.

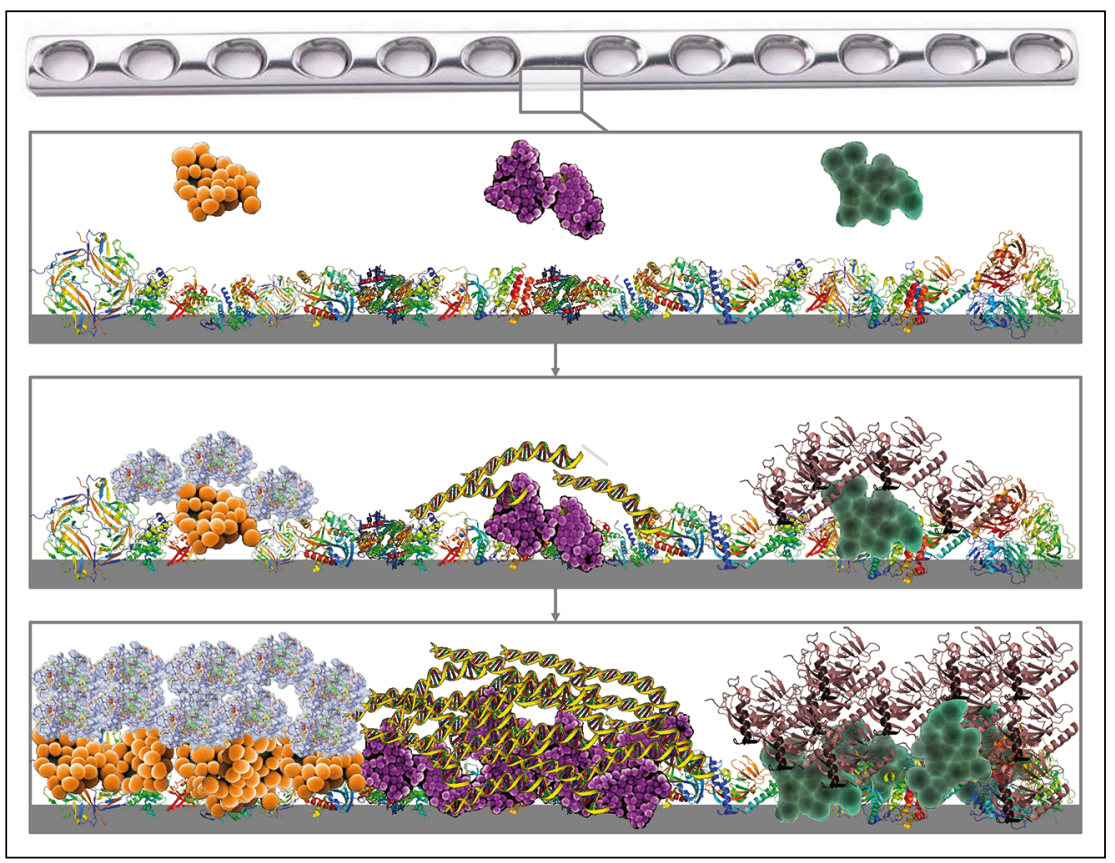

Figura 1. Adhesión y formación de biopelículas en infección asociada a material ortopédico. En el esquema se observan los tres tipos de biopelículas asociadas a material ortopédico. A izquierda, se observa una biopelícula principalmente formada por polisacáridos; al centro por ADN extracelular; a la derecha, formada por material proteico. 
Primero, la interfase entre el material y los tejidos está caracterizada por un sistema inmune disfuncional (ha sido denominada locus minoris resistentiae $)^{5}$. Este medio intersticial circundante es conocido por ser una región de inmunodepresión local, algunas veces refiriéndose a una zona fibro-inflamatoria, inmuno-incompetente, susceptible a la colonización microbiana ${ }^{1}$. Esta alteración de la inmunidad local se debe a que los micromovimientos del implante ortopédico generan detritus asociado al desgaste del material y de los tejidos, el que inhibe fuertemente la respuesta inmune ${ }^{1}$.

Segundo, los materiales ofrecen un soporte para el anclaje microbiano y la formación de biopelículas, protección en nichos superficiales o poros internos, incluso, nutrientes capaces de acelerar el crecimiento, como es el caso de algunos metales o materiales reabsorbibles que pueden liberar iones útiles para los procesos metabólicos bacterianos ${ }^{5}$. La naturaleza química intrínseca del implante y su topografía superficial pueden influir en la adhesión microbiana, pero la inmunodepresión local establece el riesgo de infección para todos los implantes ${ }^{1}$. Bajo estas circunstancias, incluso patógenos oportunistas de baja virulencia pueden llegar a colonizar la superficie de un implante . $^{5}$.

La vía de introducción más común de los agentes etiológicos que colonizarán la superficie de los implantes es la contaminación durante el procedimiento quirúrgico. Sin embargo, la vía hematógena tardía ha sido ampliamente descrita. Murdoch y cols., observaron que durante bacteriemias producidas por $S$. aureus se desarrollaron 15 infecciones asociadas a implante ortopédico en 44 pacientes con prótesis articular. Esto establece que la infección no sólo puede ocurrir al momento de la cirugía sino que durante toda la vida del implante ${ }^{25}$. Lalani y cols., reportaron que pacientes con bacteriemia secundaria a $S$. aureus e implante ortopédico tienen niveles de recaída de la infección mayores que paciente sin implante ${ }^{26}$. Se ha calculado que la tasa de infección asociada a material ortopédico después de una bacteriemia de $S$. aureus es alta, con un rango entre 30 y $40 \%{ }^{27}$.

Luego de "la carrera hacia la superficie", las bacterias estafilocóccicas establecen infecciones crónicas gracias a su capacidad de crecer en forma de biopelículas ${ }^{6}$. Las biopelículas son complejas comunidades de grupos de microrganismos auto-secretantes de una matriz de polisacáridos. Esta estructura retiene nutrientes de las células constituyentes y las protege contra la respuesta inmune $\mathrm{y}$ agentes antimicrobianos ${ }^{28}$. Está compuesta por tres componentes principales: los microrganismos (elemento clave); una superficie (para la adherencia) y un ambiente ${ }^{29}$ y puede formarse en cualquier superficie artificial que ha sido introducida en el cuerpo humano, así como en tejidos adyacentes a la superficie de los implantes ${ }^{6}$.

Staphylococcus spp. puede producir biopelículas multicapas embebidas en un glicocálix. El glicocálix se desarrolla en tejidos desvitalizados o en la superficie de implantes ortopédicos para producir la infección. La presencia de implantes es un factor predisponente, ya que se recubren precozmente con proteínas del hospedero después de la instalación, siendo éstas un recurso excelente para la adhesión bacteriana ${ }^{14}$.

La profundidad de la biopelícula puede variar desde una monocapa celular a una amplia comunidad de células rodeadas por un milieu polimérico abundante. Análisis estructurales de aquellas biopelículas de mayor grosor han evidenciado una arquitectura compleja en que las microcolonias pueden existir en distintos pilares o estructuras con forma de hongo, interconectadas a través de una red de canales. Estos canales entregan acceso a los nutrientes del medio, incluso en las zonas más profundas de la biopelícula ${ }^{14,29}$.

El glicocálix es una estructura de exopolisacáridos compleja que atrapa sustancias exógenas del medio ambiente, tales como ácidos nucleicos, proteínas, minerales, material de pared celular, etc. Es predominantemente aniónico, creando un excelente sistema de atrapamiento y concentración de minerales y nutrientes esenciales del medio ambiente ${ }^{29}$. La biopelícula, además de concentrar estos nutrientes, entrega resistencia a una serie de tácticas de remoción por parte del hospedero, tales como la resistencia a antimicrobianos y antifúngicos, al shear stress, a la fagocitosis, los radicales libres de oxígeno y las diferentes proteasas ${ }^{14}$. Las especies sensibles a la acción bactericida del cloro (hipoclorito, cloraminas y dióxido clorínico) son desactivados en las capas superficiales de la biopelícula, sin permitir su paso a capas más profundas, lugar de residencia bacteriana ${ }^{14}$. El alginato, componente de la biopelícula de $P$. aeruginosa, induce una conformación $\alpha$-hélice de los péptidos antimicrobianos, previniendo su difusión dentro de la biopelícula ${ }^{14}$.

Los organismos embebidos en esta matriz extracelular polimérica exhiben características fenotípicas alteradas con respecto a tasa de crecimiento y transcripción génica ${ }^{29}$. Las bacterias en la biopelícula presentan tasas de división menores que sus contrapartes planctónicas, siendo éste un mecanismo de defensa importante. En segundo lugar, la matriz extracelular actúa de barrera a la penetración de sustancias exógenas ${ }^{29}$. Una vez establecida la biopelícula, es prácticamente imposible erradicarla, incluso con altas dosis de antimicrobianos ${ }^{6}$. Se requiere 1.000 veces la dosis estándar de un antibacteriano para eliminar una bacteria en una biopelícula ${ }^{30}$.

\section{Bases moleculares de la adhesión y colonización}

Está bien establecido que la producción de la biopelícula posee un rol importante en la colonización de la 
superficie de los biomateriales, la evasión de la respuesta inmune del hospedero y en la resistencia al tratamiento antimicrobiano $^{5}$ (Figura 2).

El inicio de la formación de la biopelícula, requiere de la adhesión de la bacteria a la superficie del implante ortopédico, seguido de la formación de microcolonias, las cuales desarrollarán una estructura de biopelícula multicapas (estado avanzado) ${ }^{29}$. Las propiedades de la superficie, principalmente la hidrofobicidad y la presencia de cargas, juegan un rol en la adhesión y proliferación bacteriana inicial ${ }^{7}$.

La superficie del implante ortopédico, luego de ser colocada en el medio interno, acumula proteínas séricas y de la matriz extracelular (colágeno, fibronectina, fibrinógeno, vitronectina, sialoproteína ósea, elastina y trombospondina) que promueven la adherencia y colonización bacteriana, siendo éste un paso crítico en el desarrollo de las infecciones asociadas a implante ortopédico $^{5,29,31}$.

La interacción directa entre la bacteria y la superficie juega un rol crítico en las etapas tempranas del proceso de adherencia. Una vez lograda la proximidad crítica a la superficie (usualmente $1 \mathrm{~nm}$ ), la adhesión depende de las características de ésta y la naturaleza del material. La unión inicial envuelve la suma neta de fuerzas atractivas y repulsivas generadas entre la bacteria y la superficie (electroestática, interacciones hidrofóbicas, impedimento estérico, fuerzas de Van der Waals, temperatura y fuerzas hidrodinámicas $)^{29}$.

Los patógenos involucrados en este tipo de infecciones poseen una serie de proteínas de membrana encargadas de lograr la adherencia a las proteínas adsorbidas en la superficie del implante. Estas proteínas reciben el nombre de adhesinas o MSCRAMM (microbial surface components recognizing adhesive matrix molecules) y tienen como objetivo principal la adhesión al colágeno y la fibronectina, por lo que se encuentran implicadas directamente en la estabilización activa de la adhesión microbiana. El rol de los MSCRAMMs implica una adaptación evolutiva a la interacción con moléculas del hospedero ${ }^{5}$.

La adsorción bacteriana pasiva ocurre espontáneamente en la superficie de los materiales, pero el anclaje estable activo de la célula es determinado por las adhesinas (se unen a proteínas del hospedero adsorbidas en la superficie del implante $)^{2}$. Existen adhesinas específicas en la infección asociada a implantes ortopédicos. Estas confieren ventajas y contribuyen a la virulencia ${ }^{5}$.

La adherencia inicial de $S$. aureus y $S$. epidermididis, junto con la hidrofobicidad de su superficie celular, son

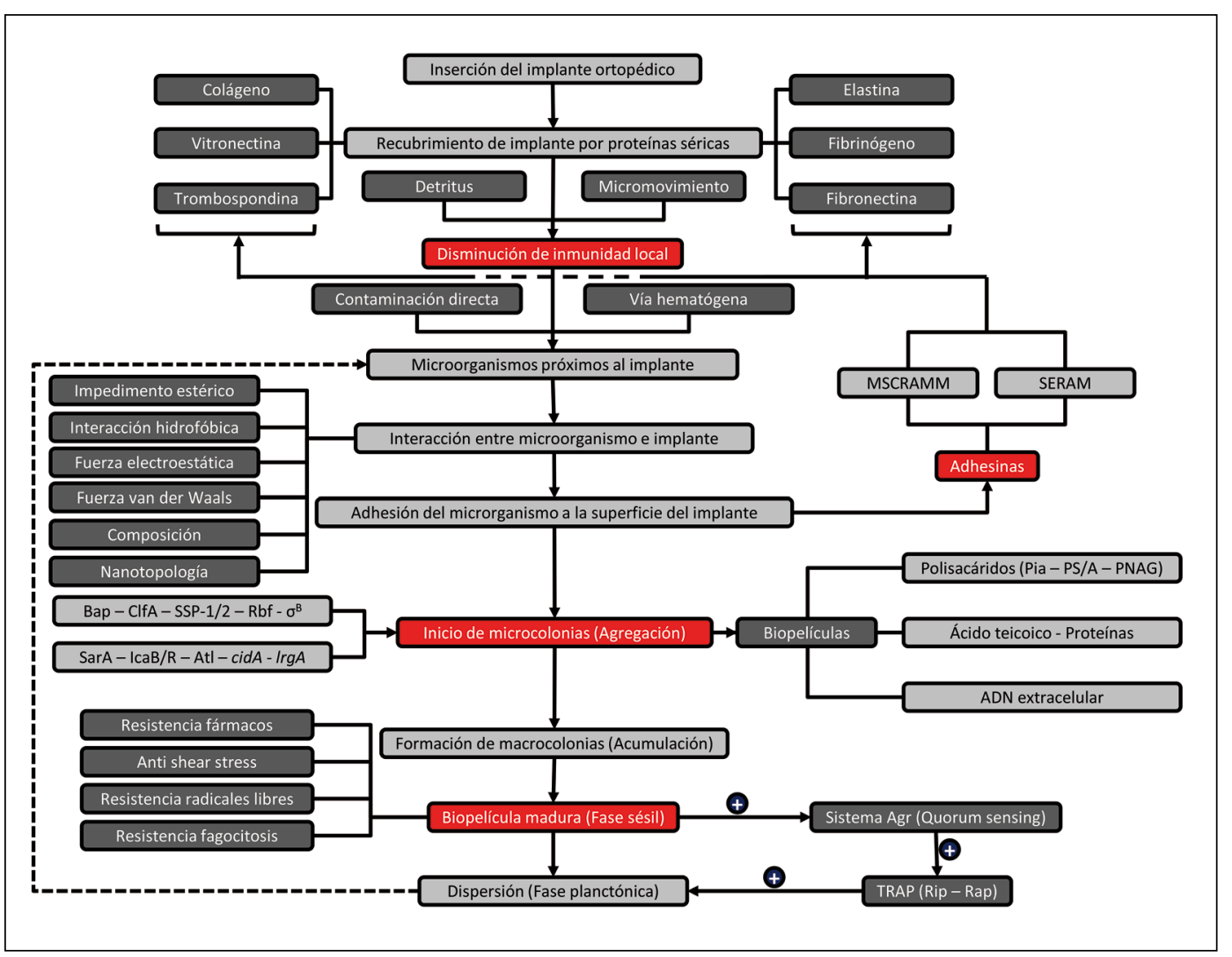

Figura 2. Infección asociada a implante ortopédico. (MSCRAMM: microbial surface components recognizing adhesive matrix molecules. Pia: polysaccharide intercelular adhesin. PS/A:polysaccharide/adhesin. PNAG: Poli- $\beta-1,6-N$-acetilglucosamina. Bap: biofilm-associated protein. ClfA: clumping factor A. SSP-1/2: Staphylococcus serineprotease. SarA: staphylococcal accessory regulator. IcaB/R: intercelullar adhesion. Atl: autolisina. Agr: accessory gene regulator. TRAP: target of RNAll-activating peptide. Rip: RNAIII inhibiting peptide. Rap: RNAIII activating peptide). 
influenciadas por dos proteínas de superficie estafilocóccicas antigénicamente relacionadas (Ssp-1 y su producto de degradación, Ssp-2), las cuales poseen una estructura tridimensional similar a las fimbrias, contribuyendo a la adherencia de las cepas ${ }^{29}$.

Staphylococcus epidermidis, tiene una proteína de unión al fibrinógeno (Fbe) codificada por el gen $f b e$. En $S$. aureus, Fbe es llamado ClfA (clumping factor A o factor aglutinante A). La diferencia entre Fbe y ClfA es que este último se une a la cadena $\gamma$ del fibrinógeno y el Fbe a la cadena $\beta$. Funcionalmente, ambas contribuyen a la adherencia de estos patógenos ${ }^{29}$.

Otra molécula asociada a la adhesión es la autolisina asociada a superficie (Atl) en $S$. aureus y AtlE en $S$. epidermidis, la cual está involucrada en la unión inicial de las células a una superficie polimérica no modificada $\mathrm{y}$ a la unión con la vitronectina ${ }^{32}$.

Los ácidos teicoicos de la pared celular también están involucrados en la adherencia de Staphylococcus. Específicamente, la adición de ésteres de D-alanina al ácido teicoico vía DltA es un factor importante en impartir un balance de cargas apropiadas en la superficie celular de las cocáceas grampositivas, permitiendo una unión inicial. La adherencia de Staphylococcus a fibronectina es mejorada por los ácidos teicoicos en una forma dosis-dependiente, por lo que se cree que el ácido teicoico actuaría como una especie de puente molecular entre las bacterias y los polímeros recubiertos por fibronectina ${ }^{29}$.

Además del grupo de adhesinas de $S$. aureus conocidas como MSCRAMM, existe un grupo de moléculas recientemente descrito llamadas SERAM (secretable expanded repertoire adhesive molecules), las cuales están asociadas de manera iónica y no covalente a la pared celular bacteriana, por lo que son secretables ${ }^{33}$. Las MSCRAMM, no así las SERAM, son proteínas receptoras ancladas a la pared celular bacteriana a través de un segmento de aminoácidos específicos leu-pro-x-thr-gly (LPXTG). La enzima sortasa A de $S$. aureus, ubicada en el lado extracelular de la membrana, escinde el motivo LPXTG, anclando covalentemente las adhesinas a los peptidoglicanos de la pared celular ${ }^{34}$.

Cabe mencionar que la adhesión intercelular no sólo es un proceso multifactorial, sino que además es redundante, ya que los mecanismo involucrados se sustituyen entre sí en diferentes etapas del proceso ${ }^{19}$. En este contexto, las adhesinas representan un importante grupo de factores de virulencia que median la interacción adhesiva entre la superficie de la célula microbiana y la superficie del implante. Éstas juegan un rol primario en las fases tempranas de la infección, logrando el tropismo tisular, la adherencia a superficies y la colonización. Sin embargo, adhesinas específicas han sido halladas actuando también como invasinas, y de hecho, interviniendo en el proceso de internalización bacteriana dentro de las células hos- pederas. Esta adhesión a superficie es un paso crítico en el inicio de la infección ${ }^{2}$.

\section{Bases moleculares de la formación de biopelículas}

La biopelícula se define como una comunidad sésil de microbios, desarrollado por una o múltiple especies. Se adhieren irreversiblemente a un sustrato viviente o no viviente, interfase entre ambos, o ambos ${ }^{29}$.

Se ha identificado una serie de factores involucrados con la formación de la biopelícula: Pia (polysaccharide intercelular adhesin: adhesina de polisacárido intercelular, codificada por el locus ica), Aap (accumulationassociated protein: proteína asociada a la acumulación), Bap (biofilm-associated protein: proteína asociada a la biopelícula) y el amplio grupo de proteínas receptoras (MSCRAMM) involucradas con la adhesión del microorganismo a la matriz extracelular del hospedero ${ }^{5}$.

La formación de la biopelícula se realiza en dos pasos. El primer paso, antes descrito, corresponde a la adhesión de las bacterias en la superficie polimérica del implante mediada por adhesinas asociadas a la pared celular. El segundo paso corresponde a la maduración mediada por factores extracelulares, con el objetivo de formar una multicapa intercelular ${ }^{35}$.

Uno de los primeros factores descritos capaces de mediar la acumulación de biopelículas en $S$. epidermidis fue el Pia. Luego, se demostró su rol en $S$. aureus. Actualmente, se sabe que el locus encargado de su síntesis está presente prácticamente en todas las cepas de $S$. aureus y ampliamente distribuido en cepas de $\mathrm{S}$. epidermidis con importancia clínica ${ }^{19}$.

El componente más estudiado de la biopelícula estafilocóccica (la más común) es un polisacárido específico denominado PNAG (Pia), el cual está compuesto por residuos de $\beta-1,6-\mathrm{N}$-acetilglucosamina (80-85\%) y una fracción aniónica con un menor contenido de residuos D-glucosaminil desacetilados que contienen fosfato $\mathrm{y}$ succinato unidos por enlaces éster $(15-20 \%)^{29,36}$.

El Pia puede ser producido in vitro desde UDP$\mathrm{N}$-acetilglucosamina utilizando el locus de adhesión intercelular (ica, intercellular adhesion). Los genes del locus ica [icaR (regulador) e icaADBC (biosintético)] son necesarios para la virulencia y formación de biopelículas, siendo sobreregulados ante condiciones anaerobias, similar a la condición en el ambiente de la biopelícula ${ }^{14}$.

IcaA tiene cuatro hélices transmembrana y actividad $\mathrm{N}$-acetilglucosaminil-transferasa, la cual aumenta 20 veces cuando se co-expresa con IcaD, el que actúa como chaperona, dirigiendo el correcto ensamblaje e inserción en la membrana celular de IcaA, actuando además como nexo entre IcaA e IcaC. Este último, permite la genera- 
ción de oligómeros de mayor largo, necesarios para su unión a Pia. Finalmente, IcaB estaría encargado de la desacetilación de $\mathrm{Pia}^{29}$.

El Pia es considerado una unión célula-célula, con la consecuente acumulación de biopelícula ${ }^{36}$. La fase más importante en la formación de la biopelícula es la acumulación y está mediada por $\mathrm{Pia}^{29}$.

En otros estudios, se describió otra adhesina polisacárida capsular (PS/A, polysaccharide/adhesin), también codificada por el operon ica, que se encargaría de mediar la fase inicial de la formación de biopelícula (la adherencia a plástico o superficies similares) ${ }^{37}$. Algunos autores plantean que Pia y PS/A son la misma entidad química ${ }^{29,37}$.

Recientemente, se ha encontrado que el Pia es producido en algunas cepas de Escherichia coli, siendo codificado por el locus pga. Homólogos del locus pga están presentes en el genoma de un amplio grupo de bacilos gramnegativos, lo que sugiere que el Pia es el polisacárido involucrado en la estabilización de las biopelículas en estas especies también ${ }^{38}$.

El otro polímero que contiene carbohidratos y ha sido aislado de las biopelículas es el ácido teicoico extracelular (EC-TA, extracelular teicoic acid $)^{36}$. También se ha visto en algunos grupos bacterianos la formación de biopelículas utilizando Aap, SasG (surface-associated Staphylococcus protein G: proteína G de Staphylococcus asociada a superficie), Esp (Enterococcal surface protein: proteína de Enterococcus de superficie) y gelatinasa (gen gelE) $^{20,35}$.

Estudios más recientes en $P$. aeruginosa indican que la liberación de $\mathrm{ADNe}$ (ADN extracelular) desde células en autolisis durante la muerte celular programada jugaría también un rol en el desarrollo de las biopelículas. La liberación de $\mathrm{ADNe}$ estaría regulada por $\operatorname{cidA}$, un gen controlador de la lisis celular. Los operones cid y lrg han mostrado tener efectos antagónicos en la actividad de la hidrolasa murina controlando la muerte celular programada, la tolerancia antibacteriana en el estado de crecimiento planctónico y en la maduración de la biopelícula en $S$. aureus ${ }^{35}$.

Se estudió la composición de la matriz de la biopelícula en cepas relacionadas directamente con infecciones asociadas a implantes ortopédicos. De once cepas productoras de biopelícula, tres presentaron altos niveles de Pia in vitro y tres con niveles detectables. Se comprobó que este polímero estabiliza la estructura intercelular de la biopelícula, ya que el uso de dispersina B desarmó la arquitectura del mismo (enzima digestiva de $\mathrm{Pia})^{36}$. El hecho de no detectarse Pia hace pensar que dichas biopelículas están compuestas principalmente de ácido teicoico y otros componentes proteicos. Es más, en estas cepas, el uso de proteinasa $\mathrm{K}$ (enzima digestiva de proteínas) desarmó la estructura de la biopelícula; no así la dispersina $\mathrm{B}$, demostrando que la estabilidad de la biopelícula en estas cepas es dada por los componentes proteicos y no por $\mathrm{Pia}^{36}$.

En otro estudio, se demostró que la biopelícula podía ser desintegrada con el uso de tripsina, demostrando que en adición a Pia, otras proteínas son necesarias para la acumulación de la biopelícula en $S$. aureus $^{39}$. Además, la desacetilación encontrada en el Pia (producida por la proteína de superficie IcaB) es esencial en la formación de la biopelícula, colonización y virulencia en modelos animales de infección asociada a implantes ortopédicos ${ }^{40}$.

En resumen, las biopelículas contienen cantidades variables de Pia (incluso puede ser ausente), pero siempre contienen componentes proteicos y ácido teicoico extracelular ${ }^{36}$. Es poco conocida la importancia relativa de las distintas moléculas. Este aspecto es vital, ya que el análisis genético falla en poder encontrar la importancia patogénica de algunos factores previamente descritos ${ }^{19}$. Estudios iniciales describen a los ácidos teicoicos como el componente más importante $(80 \%)$ de la porción sólida del glicocálix, junto a proteínas estafilocóccicas y del hospedero ${ }^{41}$.

La relación entre vancomicina y la acumulación de biopelículas es importante. El efecto de vancomicina en la inhibición o erradicación de la biopelícula de $S$. aureus es controversial. Singh y cols., demostraron que la penetración de vancomicina a través de las biopelículas es $\operatorname{limitada}^{42}$. De hecho, a pesar que vancomicina es un antiestafilocóccico comúnmente usado, la falla terapéutica de este agente contra infección por $S$. aureus resistente a meticilina (SARM) es frecuente ${ }^{35}$.

Dosis sub-letales de antibacterianos activos contra la pared celular (vancomicina) inducen la formación de biopelículas, a través de un mecanismo dependiente de autolisis en $S$. aureus no susceptibles a vancomicina. La baja concentración de antimicrobianos lograda en tejidos periféricos o profundos facilitaría la formación de biopelículas. Vancomicina posee poco poder de penetración en los tejidos. Incluso los microrganismos sensibles a vancomicina tienen posibilidad de mejorar la formación de biopelículas en sitios secuestrados. Esta es una razón probable de la falla de vancomicina en el tratamiento de infecciones causadas por SARM ${ }^{35}$.

\section{Regulación molecular de la formación de biopelícullas}

Está demostrado que Pia es un mediador importante en la formación de biopelículas en cepas de $S$. aureus; casi todas las cepas portan el operon ica $A D B C$ y producen Pia. Algunos consideran que es el regulador maestro de la formación de la biopelícula. En cambio, otros autores plantean que específicamente en infección asociada a implantes ortopédicos, serían otros los factores determinantes ${ }^{35}$. 
La utilización de vancomicina genera una sobreproducción de Pia. En cepas no susceptibles a este antimicrobiano, se ha visto que éste estimula la autolisis bacteriana, resultando en un significativo incremento en la formación de biopelícula. Este incremento se relacionó con la estimulación de los genes icaA y fnbA (sobreproducción de Pia y FnBPs) ${ }^{35}$.

La liberación de ADNe coincidente con una mejoría de la autolisis bacteriana es el factor más importante en la estimulación de la formación de biopelícula por vancomicina. Esto se asociaría a la sobreexpresión de $c i d A$ estimulada por vancomicina. Es más, el uso de ADNasa I eliminó casi totalmente el aumento de la formación de la biopelícula desencadenado por el uso de vancomicina. Un estudio reciente demostró que existe una liberación constante de $\mathrm{ADNe}$ hacia la matriz de la biopelícula, contribuyendo a su arquitectura ${ }^{35,43}$.

La liberación del ADNe está en parte mediada por la hidrolasa murina del gen $c i d A$. Este gen ha mostrado ser homólogo de las holinas (formadora de poros), involucrada en la lisis celular y ha permitido a las células de $S$. aureus de la biopelícula, lisar y liberar ADN al mileau extracelular ${ }^{44}$.

Otros factores relacionados con este proceso incluyen a las autolisinas, como la Atl, o la inducción de profagos para inducir la lisis. De hecho, en S. epidermidis, la autolisina AtlE ha demostrado ser importante en la liberación del ADN cromosomal y la subsecuente adhesión inicial durante la formación precoz de la biopelícula. En bacterias mutante atlE $E^{-}$no se liberó ADN y fue menos posible la formación de biopelícula ${ }^{45,46}$.

La cuantificación del ADNe en la biopelícula indica una correlación positiva con el aumento de producción de Pia estimulado por tratamiento con vancomicina ${ }^{35}$. Sin embargo, la sobreexpresión de cidA dirigida por vancomicina no es prolongada; de hecho, esta estimulación sostenida generaría la autolisis de toda la población. Luego de dos horas del pico de expresión de cidA, comienza a sobreexpresarse el gen $\operatorname{lrg} A$, que codifica una proteína encargada de suprimir el efecto autolítico de cidA. En conclusión, sólo una fracción de la población es "sacrificada" con tal de mejorar la formación de biopelícula. Este mecanismo permitiría a las bacterias producir biopelícula rápidamente como una respuesta poblacional protectora ante un estrés ambiental potente, como el uso de antimicrobianos ${ }^{35}$.

El aumento de la autolisis y de la formación de biopelícula vía estimulación por vancomicina es abolido en cepas carentes del gen cidA, sugiriendo que la autolisis estimulada por vancomicina es vital para la formación de biopelículas ${ }^{35}$. Algunos estudios, en que se agregó ADN exógeno, incluso de xenoespecies (E. faecalis y monocitos humanos), llevó a un aumento significativo de la formación de biopelículas en varias cepas de $S$. aureus.
Esto destaca la importancia del ADNe en la formación de biopelículas, sea proveniente del mismo $S$. aureus, otras especies bacterianas, leucocitos rondantes o incluso tejidos dañados del hospedero ${ }^{35}$.

El aumento de la formación de biopelícula también se ha visto en $S$. epidermidis a través del aumento de la producción de Pia. Los antimicrobianos formarían un complejo con TcaR (regulador de la transcripción del operon ica) el cual produciría el aumento de expresión ${ }^{47}$. En el locus homólogo de $S$. epidermidis, la regulación del ica ocurre a través de una inactivación reversible con la inserción de una secuencia (IS256) en 25 a 35\% de las variantes ${ }^{48}$. Además, existen niveles adicionales de control logrados a través de la represión transcripcional mediada por IcaR (estimulada por etanol) y el por $\sigma^{\mathrm{B}}$, producto del operon $\operatorname{sig} B$ (a su vez regulado por los operones $r s b U$ y $r s b V$ ). Sin embargo, en $S$. aureus, $\operatorname{sig} B$ no cumple tal rol, ya que los mutantes carentes de este gen no dejan de formar biopelícula ${ }^{49}$.

El IcaR se une a una región de 42 pares de base justo "río arriba" del icaA, por lo que se piensa que su rol es bloquear físicamente la unión de $\sigma^{\mathrm{B}}$, previniendo la activación del locus ica. Diversos factores ambientales juegan un rol en la regulación de ica, incluyendo los niveles de glucosa, etanol, osmolaridad, temperatura, oxígeno y presencia de antibacterianos ${ }^{14}$. La deleción de IcaR aumentó la producción de Pia casi 10 veces e incrementó la transcripción del locus ica casi 100 veces $^{50}$. Todos los factores necesarios para las fases precoces de la síntesis de biopelícula (clumping factor, fibronectin binding protein A (FnbpA) y coagulasa) son sobreregulados por $\sigma^{\mathrm{B} 51,52}$. En $S$. aureus, diversos genes de factores de virulencia son reprimidos por $\sigma^{\mathrm{B}}(\alpha$ y $\beta$-hemolisina, enterotoxina $\mathrm{B}$, SplA (proteasa de serina), SplB (proteasa de cisteína), la metaloproteasa Aur, staphopain y leucotoxina D); sólo sobreregula aquellos necesarios para adhesión y formación de biopelículas ${ }^{14}$. De hecho, la cepa RN6390, que no posee $\sigma^{\mathrm{B}}$, es deficiente en la formación de biopelícula ${ }^{53}$.

En trabajos más recientes, el rol de Pia en la formación de biopelícula ha sido cuestionado. En S. epidermidis, el gen ica no está presente en todas las cepas; de hecho, más de $30 \%$ de las biopelículas asociados a $S$. epidermidis carecen de $\mathrm{Pia}^{19}$. En un estudio en prótesis de cadera infectadas por $S$. epidermidis, sólo un tercio eran portadores del locus $i c a^{54}$.

A pesar que el locus ica es comúnmente encontrado en aislados de $S$. aureus, la correlación entre Pia y virulencia no está totalmente establecida. Diversos ensayos knockout para ica, no han podido demostrar una disminución de la virulencia o en la formación de biopelículas. En otras situaciones, se ha visto que el aumento de formación de biopelícula a causa de un estímulo por glucosa en SARM, no se correlaciona con un aumento de la transcripción de $i c a^{14}$. 
En muestra clínicas de SARM, la producción de Pia no se correlacionó con producción de biopelícula. Es más, la deleción del locus ica tampoco llevó a una inhibición de ésta. Sin embargo, en SARM, existe una correlación con producción de Pia y formación de biopelícula; además, la deleción de ica genera una abolición de la formación de esta ${ }^{55}$.

Al parecer, la contribución del locus ica al desarrollo de la biopelícula es dependiente de la cepa y del ambiente, existiendo distintos mecanismos entre Staphylococcus sensible a meticilina-(SASM) y SARM. En aquellas cepas de $S$. aureus y $S$. epidermidis en que la formación de biopelícula no es dependiente de Pia, las proteínas adhesinas y el ADNe serían los factores más importantes ${ }^{14,44}$.

El gen $r b f$ ha sido identificado recientemente; su proteína Rbf ha demostrado ser importante en la agregación multicelular durante la formación de biopelículas y además en la inducción de la formación de éstas por cloruro de sodio y glucosa, pero sin tener efecto en la transcripción de $i c a^{56}$.

Muchas especies bacterianas utilizan feromonas para comunicarse y activar ciertas vías metabólicas. Al parecer, la densidad local juega un rol fundamental en esta regulación ${ }^{57,58}$. La expresión de adhesinas, formación de biopelículas, toxinas y determinantes de la resistencia antimicrobiana son modulados por el QS (quorum sensing: sensor de quorum), sistema presente en especies grampositivas y gramnegativas 5 . El QS coordina los genes relacionados con la invasión: tropismo de los microrganismos por sitios anatómicos específicos; acumulación de bacterias bajo una biopelícula protectora; cuando las bacterias alcanzan su densidad máxima, la biopelícula se destruye y son esparcidas repartiendo la infección en su forma planctónica, para lograr la colonización de nuevos sitios 5 .

Dentro del ciclo de la formación de la biopelícula, está la liberación de células en su estado planctónico para iniciar un nuevo ciclo $^{59}$. El sistema Agr es un sensor de quorum, un regulador central de virulencia; actúa reprimiendo la expresión de genes de factores de adherencia asociados a pared celular, llevando a menor adherencia e indirectamente, menor formación inicial de biopelículas. Se ha visto que el sistema Agr estimula la expresión de péptido símil a detergente que incrementa la liberación de la biopelícula. Finalmente, su mutación incrementa la formación de ésta ${ }^{60}$.

Varios nucléotidos que actúan como segundos mensajeros (c-di-GMP, c-di-AMP, cGMP, cAMP y ppGpp) están surgiendo como importantes moléculas de señalización intracelular relacionadas con el control de la transición entre un estilo de vida planctónico a sésil, y viceversa (dispersión) ${ }^{61}$. El paradigma actual es que altas concentraciones de c-di-GMP se correlacionan con un estilo de vida sésil (formación de biopelículas), mientras que su ausencia favorece la forma planctónica ${ }^{62}$. En general, c-di-GMP juega un papel importante en la formación de biopelículas mediante la regulación de la producción de la matriz de exopolisacáridos, el control de la motilidad, agregación, adhesividad y dispersión ${ }^{61,62}$.

El sistema regulador TRAP secreta un factor regulador (Rap: RnaIII activating peptide) que incrementa la formación de biopelícula y su péptido antagonista (Rip: RnaIII inhibiting peptide) lo inhibe. Se cree que TRAP trabaja a través del sistema Agr, activando la producción de RnaIII (un efector de la respuesta de Agr) cuando las concentraciones de Rap son altas. Sin embargo, todo el efecto de TRAP es controversial e incierto aún ${ }^{63}$. Se han realizado pruebas con un péptido modificado símil a Rip (FS8), comprobando su capacidad de inhibir la formación de biopelículas, el cual podría ser utilizado clínicamente ${ }^{64}$.

El regulador accesorio estafilocóccico (SarA) es también importante, ya que los mutantes $S$. aureus y $S$. epidermidis carentes de este regulador son defectuosos en la formación de biopelículas ${ }^{49}$. La Bap (biofilm-associated protein) es requerida para la formación de biopelículas en superficies inertes ${ }^{14}$.

En un estudio que evalúo la expresión génica diferencial en cultivos de $S$. aureus planctónicos y formadores de biopelículas, se encontraron cinco genes con expresión aumentada: gen codificador de tRNA sintetasa, tres genes de respuesta a la falta de oxígeno y un gen de respuesta de estrés que codifica la ATPasa $\mathrm{ClpC}^{65}$. De hecho, la anaerobiosis incrementa fuertemente la expresión in vitro de biopelículas ${ }^{2}$.

\section{Hipótesis del genoma distribuido}

Las biopelículas sirven, a nivel poblacional, como factores de virulencia, ya que proveen a sus bacterias residentes con atributos que de forma individual no poseen. La mayoría de estos rasgos de virulencia son protectores para la bacteria, permitiendo su persistencia en el hospedero contra el efecto del sistema inmune innato y adaptativo ${ }^{66}$.

Las biopelículas proveen un ambiente ideal para altos niveles de transferencia génica entre las bacterias residentes, tanto entre cepas de una especie como entre especies relacionadas. Casi todos los patógenos bacterianos formadores de biopelícula contienen mecanismos de transferencia génica horizontal inducibles, que requieren energía y que sirven con un propósito no nutritivo (opuesto a aquellos casos en que el $\mathrm{ADN}$ es utilizado como simple fuente de nutrientes) ${ }^{66}$.

La hipótesis del genoma distribuido postula que las biopelículas bacterianas asociadas a infecciones crónicas están compuestas de múltiples cepas de una especie (a veces incluso son comunidades polimicrobianas o polireino) y que la transferencia génica horizontal en tiempo 
real entre estas cepas constituyentes (y especies) llevan a una generación contínua de una nube de nuevas cepas con novedosas combinaciones genéticas, proveyendo a la comunidad bacteriana los medios para frustrar la respuesta inmune adaptativa del hospedero ${ }^{66}$.

La transferencia génica horizontal es definida como el movimiento de genes entre dos células bacterianas. La célula donante no requiere necesariamente ser viable al momento de la transferencia ${ }^{66}$. La transferencia de uno o más bloques pequeños de $\mathrm{ADN}$ donante dentro de la célula recipiente proveen sólo de un remplazo parcial del cromosoma bacteriano receptor. Cada cepa contiene entre 200 y 400 inserciones/deleciones (indels) a través de su cromosoma. Se considera que cada cromosoma es un mosaico respecto a sus genes originales. Se ha calculado que $S$. aureus posee 246 diferencias génicas en promedio entre cada par de cepas que han sido secuenciadas. De hecho, más de dos tercios de los genes de la especie se encuentra sólo en un subgrupo de cepas ${ }^{66}$.

Los genes adquiridos a través de transferencia génica horizontal producen mosaicismo cromosómico en el cual cada parte del cromosoma que fue adquirida horizontalmente posee un ancestro diferente ${ }^{66}$. La mayoría de las especies bacterianas patogénicas poseen mecanismos de transferencia génica horizontal, sin importar barreras entre especies. Este es uno de los argumentos que apoya fuertemente la hipótesis del genoma distribuido ${ }^{66}$.

Desde un punto de vista teleológico, las bacterias se dan cuenta que deben cambiar algunas características para poder sobrevivir, por lo que activan sistemas energéticos para incrementar la posibilidad de recombinación genética, muy similar a las especies sexuadas, con el fin de producir nuevos organismos, ventajas selectivas bajo las condiciones prevalentes en el hospedero, asegurando así la sobrevivencia de la población bacteriana y el pool génico bacteriano como un todo ${ }^{66}$.

Los estados patogénicos crónicos universalmente han adoptado un fenotipo hacia la producción de biopelículas. La creación cooperativa de esta matriz por una comunidad bacteriana es un factor de virulencia a nivel poblacional, ya que para el hospedero es más dificultoso erradicarla que a las bacterias en estado planctónico. Una vez iniciado, la biopelícula actúa como un organismo único viviente y dinámico que puede crecer, cambiar sus propiedades físicas en respuesta al ambiente, evolucionar a través de mutaciones para ser más adaptado a los desafíos ambientales e incorporar otras especies patogénicas en una comunidad polimicrobiana integrada ${ }^{66}$.

La matriz de polisacáridos es altamente viscoelástica y puede rápidamente ser remodelada en respuesta a cambios en el medio ambiente, de forma similar al hueso endocondral en que la fuerza aplicada es capaz de modificar los componentes celulares ${ }^{66}$.

La transformación es 10.000 veces más frecuente en biopelículas en comparación con formas planctónicas. Esto puede ser explicado ya que uno de los mayores constituyentes de la matriz de la biopelícula es el ADNe, lo que provee de una matriz cruda en material genético. Además, las células bacterianas están yuxtapuestas, lo que favorece cualquier intercambio génico ${ }^{66}$.

\section{Estrategia de prevención}

La caracterización genética y molecular de las bacterias relacionadas con infecciones asociadas a implantes ortopédicos tiene como objetivo el desarrollo de biomateriales resistentes a la infección (materiales cargados de antimicrobianos, superficies repelentes a adhesinas bacterianas específicas o vacunas dirigidas hacia estas moléculas) ${ }^{67}$.

Dentro de las estrategias novedosas para prevenir este tipo de infecciones, está la utilización de materiales bioactivos con naturaleza intrínsecamente antimicrobiana (ej: cobre). Actualmente, los revestimientos bioactivos representan la forma más efectiva para modificar la superficie y prevenir la formación de biopelículas. Están basados en sustancias con propiedades bacteriostáticas/bactericidas actualmente usadas como desinfectantes tópicos (plata, cobre, clorhexidina, triclosán) o antimicrobianos (gentamicina, rifampicina, teicoplanina, vancomicina, solos o en combinación). Sin embargo, la cinética de estos antimicrobianos y la posible presión evolutiva hacia la resistencia es un tema no resuelto ${ }^{5,67}$.

El uso correcto de antimicrobianos convencionales puede eliminar las células en fase planctónica y los tratamientos de la superficie del material pueden disminuir la probabilidad del microrganismo de sobrevivir en la superficie del implante ${ }^{5}$. Sin embargo, la alteración de la superficie con tal de disminuir la infección es beneficiosa en el corto plazo, pero a largo plazo, puede llegar a alterar la integración del implante al tejido óseo ${ }^{5}$.

El uso de antimicrobianos y recubrimientos son las dos técnicas más comúnmente usadas para prevenir la adhesión y difusión de microrganismos en las superficies ${ }^{7}$. El "patrón de oro" para liberación de antimicrobianos de forma local es el cemento óseo impregnado con antibacterianos (polimetilmetacrilato: PMMA). El uso de antibacterianos cargados en el PMMA permite la liberación de altas concentraciones de antibacterianos en el área afectada sin causar toxicidad sistémica ${ }^{31}$. El uso de cemento con antibacterianos ha demostrado ser útil de forma precoz. Existe la preocupación en etapas tardías, cuando la concentración de antimicrobiano lograda es mucho menor y pudiera contribuir a la selección de especies con resistencia antimicrobiana ${ }^{1,23}$.

La utilización de gentamicina (antibacteriano más frecuentemente usado) muestra una tasa de liberación inicial que tiende a aumentar en superficies rugosas, mientras 
que la cantidad total liberada del antibacteriano en una semana es directamente proporcional a la porosidad del cemento. Sin embargo, se ha visto que la formación de la biopelícula en el cemento óseo con gentamicina muestra cambios no relacionados con la cinética de liberación este fármaco. Por lo tanto, la formación de la biopelícula en cemento óseo no sólo se relaciona con la liberación del antibacteriano, sino que es dependiente también de otras propiedades (rugosidad y porosidad) ${ }^{23}$. De hecho, a mayor rugosidad disminuye la liberación de las bacterias muertas por el antimicrobiano, actuando éstas como substrato para la formación de biopelículas ${ }^{23}$.

En resumen, existen problemas asociados al uso de antibióticos locales ${ }^{27}$ :

- Las concentraciones de antimicrobianos se mantienen por períodos definidos, produciendo al largo plazo, menores concentraciones. Potencialmente favorecen la resistencia antimicrobiana.

- Los antimicrobianos no penetran las biopelículas, forma más común que adoptan estas infecciones.

- La reacción exotérmica inactiva muchos fármacos, limitando el arsenal terapéutico.

- Superficies covalentemente unidas a antibacterianos no evitan la adhesión bacteriana, ya que las macromoléculas liberadas y los microrganismos muertos se acumulan fácilmente en la superficie y bloquean los grupos funcionales de los antimicrobianos, además de favorecer la adhesión bacteriana.

- Los recubrimientos de antimicrobianos son un avance prometedor, pero son pobremente biocompatibles.

Incluso, algunos estudios han demostrado que el uso de dosis sub-letales de antibacterianos (vancomicina) puede exacerbar la formación de la biopelícula ${ }^{68}$. El uso de vancomicina covalentemente unida a una aleación de titanio, previene la colonización y formación de biopelículas por $S$. epidermidis, pero su biocompatibilidad ha sido cuestionada ${ }^{31}$.

A diferencia de vancomicina, el uso de nano partículas de sílice liberadoras de óxido nítrico $(\mathrm{NO})$ in vitro para destruir células protegidas por biopelícula ( $P$. aeruginosa, E. coli, S. aureus, S. epidermidis y Candida albicans) demostró más de $99 \%$ de efectividad. Las pruebas de citotoxicidad revelaron que a altas dosis inhiben la proliferación de fibroblastos, lo que podría limitar su aplicabilidad en ortopedia y traumatología ${ }^{28}$.

El uso de polímeros zwitteriónicos como superficie de recubrimiento reduce la formación de la biopelícula a largo plazo entre 93-95\% (192 a 240 h de cultivo). Esto estaría explicado, ya que este polímero logra evitar en $100 \%$ la adsorción de proteínas no específicas en la superficie del implante ${ }^{69}$.

El recubrimiento con péptidos antimicrobianos (AMPs o antimicrobial peptides) es una alternativa a los antimi- crobianos convencionales por su amplio espectro y baja estimulación de resistencia, además de poder modular la respuesta inmune del hospedero. Sin embargo, la biocompatibilidad es un tema no resuelto aún ${ }^{68}$.

Otra forma de prevenir la adhesión bacteriana es alterar la química o micro/nanotopología de la capa externa del implante. Dentro de las alteraciones químicas se encuentra el recubrimiento con surfactantes, proteínas (albúmina), polisacáridos hidrofílicos cargados negativamente (hialuronano y heparina), con el fin de evitar la adhesión o repeler la superficie bacteriana ${ }^{1}$. La heparina ha disminuído la adhesión de bacterias a la superficie de lentes intraoculares. Se supone que la interacción entre $S$. epidermidis y fibronectina ocurre en un único sitio en sentido C-terminal, el cual es específicamente inhibido por la heparina ${ }^{70,71}$. Estos estudios sugieren un rol de la heparina como un inhibidor específico de la adhesión de S. epidermidis a la superficie de los biomateriales ${ }^{5}$.

Otro enfoque prometedor es el uso de compuestos cuaternarios de amonio para generar superficie autoesterilizantes. Los grupos funcionales capaces de dañar las membranas celulares se unen covalentemente a un polímero transportador y actúan mientras se encuentran ancladas a la superficie del implante y no mientras son liberadas como moléculas libres en la región periprotésica ${ }^{1}$. También se ha demostrado una menor adhesión bacteriana con el uso de superficies tratadas con una capa externa de dióxido de titanio anatasa ${ }^{1}$.

Finalmente, una de las estrategias más prometedoras es el uso de vacunas y la terapia génica. El uso de oligonucleótidos antisentido se ha utilizado inicialmente para interferir con la expresión de genes relacionados con la resistencia a antimicrobianos ${ }^{72,73}$.

\section{Conclusiones}

En ortopedia y traumatología, la gran mayoría de las infecciones se asocia al uso de implantes, debido a que representan un sitio de debilidad de las defensas del hospedero. Las proyecciones indican que la utilización de implantes ortopédicos y las infecciones asociadas a éstos están destinadas a aumentar en las próximas décadas, exigiendo nuevas estrategias terapéuticas y preventivas, debido a las consecuencias devastadoras desde el punto de vista funcional, social y económico de las infecciones. El estudio y la comprensión de los factores de virulencia, su importancia relativa y sus mecanismos de regulación pueden apoyar nuevas estrategias.

Antiguas estrategias para evitar la contaminación y el uso de antimicrobianos sistémicos perioperatorios debe sumarse a nuevas estrategias emergentes centradas en la reducción de la vulnerabilidad intrínseca de los implantes a la colonización bacteriana. 
La mejor estrategia para combatir la formación de biopelículas en los implantes ortopédicos es evitar que se produzcan. Esto debería ser posible, ya que las infecciones bacterianas son inicialmente planctónicas, y sólo después logran elaborar una biopelícula. Para lograr esta estrategia preventiva, se requerirá de un esfuerzo multidisciplinario entre la ingeniería, ortopedia y microbiología, con tal de lograr el desarrollo de "implantes inteligentes", capaces de detectar la presencia de microorganismos y evitar su adherencia, incluso lograr su erradicación una vez adheridas.

Sin embargo, en el medio nacional deben darse los primeros pasos en una caracterización global de la etiología y de los factores de virulencia asociados a las infecciones de los implante ortopédicos para poder realizar un análisis comparativo con los hallazgos realizados a nivel internacional, con tal de poder plantear estrategias locales con el fin de reducir las tasas de infección.

El conocimiento de las bases moleculares de la infección asociada a implantes ortopédicos, además de permitir plantear estrategias novedosas y modernas de control de infección, deben entregar al ortopedista las bases fundamentadas para el manejo clínico de la infección, tratando de eliminar antiguas prácticas en que no se consideran las características particulares de este tipo de infecciones.

\section{Resumen}

La infección asociada a la utilización de implantes ortopédicos es la principal complicación asociada a estos dispositivos y es un desafío aún sin resolver. La frecuencia de infección asociada a implante ortopédico es relativamente baja, estimada en un rango de 0,5 a $5 \%$. Sin embargo, sus consecuencias son devastadoras para el paciente y las instituciones de salud. La mayoría de las infecciones son causadas por microorganismos aerobios grampositivos pertenecientes al género Staphylococcus. Estas bacterias establecen infecciones crónicas gracias a su capacidad de adhesión y formación de biopelículas, complejas comunidades en una matriz de polisacáridos. La biopelícula retiene nutrientes y protege a las bacterias contra la respuesta inmune y agentes antimicrobianos. El estudio de las características moleculares y la regulación de la formación de biopelículas es vital para el entendimiento del manejo clínico juicioso y el desarrollo de estrategias novedosas para la prevención de infección.

\section{Referencias bibliográficas}

1.- Campoccia D, Montanaro L, Arciola C R. The significance of infection related to orthopedic devices and issues of antibiotic resistance. Biomaterials 2006; 27 (11): 2331-9.

2.- Montanaro L, Speziale P, Campoccia D, Ravaioli S, Cangini I, Pietrocola G, et al. Scenery of Staphylococcus implant infections in orthopedics. Future Microbiol 2011; 6 (11): 1329-49.

3.- Zimmerli W, Trampuz A, Ochsner P E. Prosthetic-joint infections. N Engl J Med 2004; 351 (16): 1645-54.

4.- Printzen G. Relevance, pathogenicity and virulence of microorganisms in implant related infections. Injury 1996; 27 (Suppl 3): SC9-SC15.

5.- Montanaro L, Campoccia D, Arciola C R. Advancements in molecular epidemiology of implant infections and future perspectives. Biomaterials 2007; 28 (34): 5155-68.

6.- Ehrlich G D, Stoodley P, Kathju S, Zhao Y, McLeod B R, Balaban N, et al. Engineering approaches for the detection and control of orthopaedic biofilm infections. Clin Orthop Relat Res 2005; 437: 59-66.

7.- Gao G, Lange D, Hilpert K, Kindrachuk J, Zou Y, Cheng J T, et al. The biocompatibility and biofilm resistance of implant coatings based on hydrophilic polymer brushes conjugated with antimicrobial peptides. Biomaterials 2011; 32 (16): 3899-909.

8.- Oteiza O'R F, Brenner P. Infecciones en cirugía de artroplastía de cadera: Resultados del sistema de vigilancia epidemiológica de las infecciones intrahospitalarias. 1996-1996. Rev Chilena Infectol 2000; 17 (2): 109-14.

9.- Fica A, Llanos C, Luzoro A, De la Barrera C, Miranda G. Infecciones en prótesis articulares. Rev Chilena Infectol 2000; 17 (2): 115-21.

10.- Irribarren $\mathrm{O}$, Álvarez $\mathrm{A}$, Rodríguez $\mathrm{C}$, Ferrada M, Hernández H, Dorn L. Costo y desenlace de la infección de artroplastía de cadera. Estudio de caso y control. Rev Chilena Infectol 2007; 24 (2): 125-30.

11.- Zimmerli W, Waldvogel F A, Vaudaux P, Nydegger U E. Pathogenesis of foreign body infection: description and characteristics of an animal model. J Infect Dis 1982; 146 (4): 487-97.

12.- Percival S L, Bowler P,Woods E J. Assessing the effect of an antimicrobial wound dressing on biofilms. Wound Rep Reg 2008; 16: 52-7.

13.- Rohde H, Kalitzky M, Kroger N, Scherpe S, Horstkotte M A, Knobloch J K, et al. Detection of virulence-associated genes not useful for discriminating between invasive and commensal Staphylococcus epidermidis strains from a bone marrow transplant unit. J Clin Microbiol 2004; 42 (12): 5614-9.

14.- Brady R A, Leid J G, Calhoun J H, Costerton J W, Shirtliff M E. Osteomyelitis and the role of biofilms in chronic infection. FEMS Immunol Med Microbiol 2008; 52 (1): 13-22.

15.- Larson E L, McGinley K J, Foglia A R, Talbot G H, Leyden J J. Composition and antimicrobic resistance of skin flora in hospitalized and healthy adults. J Clin Microbiol 1986; 23 (3): 604-8.

16.- Arciola C R, An Y H, Campoccia D, Donati M E, Montanaro L. Etiology of implant orthopaedic infections: a survey on 1027 clinical isolates. Int J Artif Organs 2005; 28 (11): 1091-100.

17.- Arciola C R, Campoccia D, Baldassarri L, Donati M E, Pirini V, Gamberoni S, et al. Detection of biofilm formation in Staphylococcus epidermidis from implant infections. Comparison of a PCR method which recognizes the presence of ica genes with two classic phenotypic methods. J Biomed Mater Res A 2006; 76 (2): 425-30.

18.- Arciola C R, An Y H, Campoccia D, Baldi R, Donati M E, Montanaro L. Etiology of implant orthopedic infections: A survey on 1027 clinical isolates. Int J Artif Organs 2005; 28 (11): 1091-100

19.- Rohde H, Burandt E C, Siemssen N, Frommelt L, Burdelski C, Wurster S, et al. Polysaccharide intercellular adhesin or protein factors in biofilm accumulation of Staphylococcus epidermidis and Staphylococcus aureus isolated from prosthetic hip and knee 
joint infections. Biomaterials 2007; 28 (9): 1711-20.

20.- Arciola C R, Baldassarri L, Campoccia D, Creti R, Pirini V, Huebner J. Strong biofilm production, antibiotic multi-resistance and high gelE expression in epidemic clones of Enterococcus faecalis from orthopaedic implant infections. Biomaterials 2008; 29 (5): 580-6.

21.- Baquero F. Gram-positive resistance: challenge for the development of new antibiotics. $J$ Antimicrob Chemother 1997; 39 (Suppl. A): 1-6.

22.- Campoccia D, Montanaro L, Baldassarri L, An Y H, Arciola C R. Antibiotic resistance in Staphylococcus aureus and Staphylococcus epidermidis clinical isolates from implant orthopedic infections. Int J Artif Organs 2005; 28 (11): 1186-91.

23.- van de Belt $H$, Neut $D$, Schenk $W$, van Horn J R, van Der Mei H C, Busscher H J. Staphylococcus aureus biofilm formation on different gentamicin-loaded polymethylmethacrylate bone cements. Biomaterials 2001; 22 (12): 1607-11.

24.- Southwood R T, Rice J L, McDonald P J, Hakendorf P H, Rozenbilds M A. Infection in experimental hip arthroplasties. J Bone Joint Surg Br 1985; 67 (2): 229-31.

25.- Murdoch D R, Roberts S A, Fowler Jr V G Jr, Shah M A, Taylor S L, Morris A J. Infection of orthopedic prostheses after Staphylococcus aureus bacteremia. Clin Infect Dis 2001; 32 (4): 647-9.

26.- Lalani T, Chu V H, Grussemeyer C A, Reed S D, Bolognesi M P, Friedman J Y. Clinical outcomes and costs among patients with Staphylococcus aureus bacteremia and orthopedic device infections. Scand J Infect Dis 2008; 40 (11-12): 973-7.

27.- Sendi P, Banderet F, Graber P, Zimmerli W. Periprosthetic joint infection following Staphylococcus aureus bacteremia. J Infect 2011; 63 (1): 17-22.

28.- Hetrick E M, Shin J H, Paul H S, Schoenfisch M H. Anti-biofilm efficacy of nitric oxide-releasing silica nanoparticles. Biomaterials 2009; 30 (14): 2782-9.

29.- Costerton J W, Lewandowski Z, Caldwell D E, Korber D R, Lappin-Scott H M. Microbial biofilms. Annu Rev Microbiol 1995; 49: 711-45.

30.- Smith A W. Biofilms and antibiotic therapy: is there a role for combating bacterial resistance by the use of novel drug delivery systems? Adv Drug Deliv Rev 2005; 57: 1539-50.

31.- Antoci V Jr, Adams C S, Parvizi J, Davidson H M, Composto R J, Freeman T A, et al. The inhibition of Staphylococcus epidermidis biofilm formation by vancomycinmodified titanium alloy and implications for the treatment of periprosthetic infection. Biomaterials 2008; 29 (35): 4684-90.

32.- Heilmann C, Hussain M, Peters G, Gotz F.
Evidence for autolysin mediated primary attachment of Staphylococcus epidermidis to a polystyrene surface. Mol Microbiol 1997; 24: 1013-24.

33.- Chavakis T, Wiechmann K, Preissner K T, Herrmann M. Staphylococcus aureus interactions with the endothelium: the role of bacterial "secretable expanded repertoire adhesive molecules" (SERAM) in disturbing host defense systems. Thromb Haemost 2005; 94 (2): 278-85.

34.- Suree N, Liew C K, Villareal V A, Thieu W, Fadeev E A, Clemens J J. The structure of the Staphylococcus aureus sortase-substrate complex reveals how the universally conserved LPXTG sorting signal is recognized. J Biol Chem 2009; 284 (36): 24465-77.

35.- Hsu C Y, Lin M H, Chen C C, Chien S C, Cheng Y H, Su I N. Vancomycin promotes the bacterial autolysis, release of extracellular DNA, and biofilm formation in vancomycinnon-susceptible Staphylococcus aureus. FEMS Immunol Med Microbiol 2011; 63 (2): 236-47.

36.- Sadovskaya I, Chaignon P, Kogan G, Chokr A, Vinogradov E, Jabbouri S. Carbohydratecontaining components of biofilms produced in vitro by some staphylococcal strains related to orthopaedic prosthesis infections. FEMS Immunol Med Microbiol 2006; 47 (1): 75-82.

37.- Maira-Litran T, Kropec A, Goldmann D, Pier G B. Biologic properties and vaccine potential of the staphylococcal poly-N-acetyl glucosamine surface polysaccharide. Vaccine 2004; 22: 872-9.

38.- Wang X, Preston J F III, Romeo T. The pgaABCD locus of Escherichia coli promotes the synthesis of a polysaccharide adhesin required for biofilm formation. J Bacteriol 2004; 186: 2724-34.

39.- Fluckiger U, Ulrich M, Steinhuber A, Döring G, Mack D, Landmann R, et al. Biofilm formation, icaADBC transcription, and polysaccharide intercellular adhesin synthesis by staphylococci in a device-related infection model. Infect Immun 2005; 73: 1811-9.

40.- Vuong C, Kocianova S, Voyich J M, Yao Y, Fischer E R, DeLeo F R, et al. A crucial role for exopolysaccharide modification in bacterial biofilm formation, immune evasion, and virulence. J Biol Chem 2004; 279: 54881-6.

41.- Akiyama H, Ueda M, Kanzaki H, Tada J, Arata J. Biofilm formation of Staphylococcus aureus strains isolated from impetigo and furuncle: role of fibrinogen and fibrin. J Environ Pathol Toxicol 1997; 16: 2-10.

42.- Singh R, Ray P, Das A, Sharma M. Penetration of antibiotics through Staphylococcus aureus and Staphylococcus epidermidis biofilms. J Antimicrob Chemother 2010; 65: 1955-8.

43.- Tetz V V, Tetz G V. Effect of extracellular
DNA destruction by DNase I on characteristics of forming biofilms. DNA Cell Biol 2010; 29: 399-405.

44.- Rice K C, Mann E E, Endres J L, Weiss E C, Cassat J E, Smeltzer M S, et al. The cidAmurein hydrolase regulator contributes to DNA release and biofilm development in Staphylococcus aureus. Proc Natl Acad Sci USA 2007; 104 8113-8.

45.- Webb J S, Thompson L S, James S, Charlton T, Tolker-Nielsen T, Koch B, et al. Cell death in Pseudomonas aeruginosa biofilm development. J Bacteriol 2003; 185: 4585-92.

46.- Qin Z, Ou Y, Yang L, Zhu Y, Tolker-Nielsen T, Molin S, et al. Role of autolysin-mediated DNA release in biofilm formation of Staphylococcus epidermidis. Microbiology 2007; 153: 2083-92.

47.- Chang Y M, Jeng W Y, Ko T P, Yeh Y J, Chen C K, Wang A H. Structural study of TcaR and its complexes with multiple antibiotics from Staphylococcus epidermidis. Proc Natl Acad Sci USA 2010; 107: 8617-22.

48.- Conlon K M, Humphreys H, O'Gara J P. Inactivations of rsbU and sarA by IS256 represent novel mechanisms of biofilm phenotypic variation in Staphylococcus epidermidis. J Bacteriol 2004; 186: 6208-19.

49.- Valle J, Toledo-Arana A, Berasain C, Ghigo J M, Amorena B, Penades J R, et al. SarA and not sigmaB is essential for biofilm development by Staphylococcus aureus. Mol Microbiol 2003; 48: 1075-87.

50.- Jefferson K K, Pier D B, Goldmann D A, Pier G B. The teicoplanin-associated locus regulator (TcaR) and the intercellular adhesin locus regulator (IcaR) are transcriptional inhibitors of the ica locus in Staphylococcus aureus. J Bacteriol 2004; 186: 2449-56.

51.- Nair S P, Bischoff M, Senn M M, Berger-Bachi B. The sigma B regulon influences internalization of Staphylococcus aureus by osteoblasts. Infect Immun 2003; 71 : 4167-70.

52.- Nicholas R O, Li T, McDevitt D, Marra A, Sucoloski S, Demarsh P L, et al. Isolation and characterization of a sigB deletion mutant of Staphylococcus aureus. Infect Immun 1999; 67: 3667-9.

53.- Cassat J, Dunman P M, Murphy E, Projan S J, Beenken K E, Palm K J, et al. Transcriptional profiling of a Staphylococcus aureus clinical isolate and its isogenic agr and sarA mutants reveals global differences in comparison to the laboratory strain RN6390. Microbiology 2006; 152: 3075-90.

54.- Nilsdotter-Augustinsson A, Koskela A, Ohman L, Soderquist B. Characterization of coagulase-negative staphylococci isolated from patients with infected hip prostheses: use of phenotypic and genotypic analyses, including tests for the presence of the ica operon. Eur J Clin Microbiol Infect Dis 2007; 26: 255-65. 
55.- O’Neill E, Pozzi C, Houston P, Smyth D, Humphreys H, Robinson D A, et al. Association between methicillin susceptibility and biofilm regulation in Staphylococcus aureus isolates from device-related infections. J Clin Microbiol 2007; 45: 1379-88.

56.- Lim Y, Jana M, Luong T T, Lee C Y. Control of glucose and $\mathrm{NaCl}$-induced biofilm formation by rbf in Staphylococcus aureus. J Bacteriol 2004; 186: 722-9.

57.- Winzer K, Williams P. Quorum sensing and the regulation of virulence gene expression in pathogenic bacteria. Int J Med Microbiol 2001; 291 (2): 131-43.

58.- Donabedian H. Quorum sensing and its relevance to infectious diseases. J Infect 2003; 46 (4): 207-14.

59.- Mack D, Becker P, Chatterjee I, Dobinsky S, Knobloch J K, Peters G. Mechanisms of biofilm formation in Staphylococcus epidermidis and Staphylococcus aureus: functional molecules, regulatory circuits, and adaptive responses. Int J Med Microbiol 2004; 294 (2-3): 203-12.

60.- Chan W C, Coyle B J, Williams P. Virulence regulation and quorum sensing in staphylococcal infections: competitive AgrC antagonists as quorum sensing inhibitors. J Med Chem 2004; 47: 4633-41.

61.- Kalia D, Merey G, Nakayama S, Zheng Y, Zhou J, Luo Y, et al. Nucleotide, c-di-GMP, c-di-AMP, cGMP, cAMP, (p)ppGpp signaling in bacteria and implications in pathogenesis Chem Soc Rev 2013; 42 (1): 305-41.

62.- Roy A B, Petrova O E, Sauer K. The phosphodiesterase DipA (PA5017) is essential for Pseudomonas aeruginosa biofilm dispersion. J Bacteriol 2012; 194 (11): 2904-15.

63.- Korem M, Gov Y, Kiran M D, Balaban N. Transcriptional profiling of target of RNAIIIactivating protein, a master regulator of staphylococcal virulence. Infect Immun 2005; 73: 6220-8.

64.- Simonetti O, Cirioni O, Mocchegiani F, Cacciatore I, Silvestri C, Baldassarre L, et al. The efficacy of the quorum sensing inhibitor FS8 and tigecycline in preventing prosthesis biofilm in an animal model of staphylococcal infection. Int J Mol Sci 2013; 14 (8): 16321-32.

65.- Beenken K E, Dunman P M, McAleese F, Macapagal D, Murphy E, Projan S J, et al. Global gene expression in Staphylococcus aureus biofilms. J Bacteriol 2004; 186: 4665-84.

66.- Ehrlich G D, Ahmed A, Earl J, Hiller N L, Costerton J W, Stoodley P, et al. The distributed genome hypothesis as a rubric for understanding evolution in situ during chronic bacterial biofilm infectious processes. FEMS Immunol Med Microbiol 2010; 59 (3): 269-79.

67.- Campoccia D, Montanaro L, Arciola C R. A review of the clinical implications of antiinfective biomaterials and infection-resistant surfaces. Biomaterials 2013; 34 (33): 8018-29.
68.- Nejadnik M R, van der Mei H C, Norde W, Busscher H J. Bacterial adhesion and growth on a polymer brush-coating. Biomaterials 2008; 29 (30): 4117-21.

69.- Cheng G, Li G, Xue H, Chen S, Bryers J D, Jiang S. Zwitterionic carboxybetaine polymer surfaces and their resistance to long-term biofilm formation. Biomaterials 2009; 30 (28): 5234-40.

70.- Arciola C R, Radin L, Alvergna P, Cenni E, Pizzoferrato A. Heparin surface treatment of poly(methylmethacrylate) alters adhesion of a Staphylococcus aureus strain: utility of bacterial fatty acid analysis. Biomaterials 1993; 14 (15): 1161-4.

71.- Bustanji Y, Arciola C R, Conti M, Mandello E, Montanaro L, Samori B. Dynamics of the interaction between a fibronectin molecule and a living bacterium under mechanical force. Proc Natl Acad Sci USA 2003; 100: 13292-7.

72.- Sarno R, Ha H, Weinsetel N, Tolmasky M E. Inhibition of aminoglycoside 60-N-acetyltransferase type Ib-mediated amikacin resistance by antisense oligodeoxynucleotides. Antimicrob Agents Chemother 2003; 47 (10): 3296-304.

73.- White D G, Maneewannakul K, von Hofe E, Zillman M, Eisenberg W, Field A K, et al. Inhibition of the multiple antibiotic resistance (mar) operon in Escherichia coli by antisense DNA analogs. Antimicrob Agents Chemother 1997; 41 (12): 2699-704. 